\title{
A Case of Hereditary Gastrointestinal Stromal Tumor (KIT Mutation p.Asp820Tyr) in a Portuguese Family and a Good Response to Imatinib - An Update
}

\author{
Vítor Devezas ${ }^{1,2}$, Hugo Santos-Sousa ${ }^{1,2}$, Silvestre Carneiro ${ }^{1,2,3}$, Elisabete Barbosa ${ }^{1,2,4}$, José Barbosa $a^{1,2,5}$
}

Corresponding author:

Vítor Bruno dos Santos Devezas, MD

Centro Hospitalar Universitário

de Săo Joăo

Serviço de Cirurgia Geral

Alameda Prof. Hernâni Monteiro

4200-319, Porto, Portugal

Tel.: +351937427911

Fax: + 351225025766
E-mail: vitor.devezas7@gmail.com

'General Surgery, Department of Surgery, Centro Hospitalar Universitário de Săo Joăo (CHUSJ) - Oporto/Portugal

${ }^{2}$ Faculdade de Medicina da Universidade do Porto, CHUSJ - Oporto, Portugal

${ }^{3}$ Director of Central Operation Room, Department of Surgery, CHUSJ - Oporto, Portugal

${ }^{4}$ Director of General Surgery, Department of Surgery, CHUSJ - Oporto, Portugal

${ }^{5}$ Department of General Surgery, Responsible of the Esophageal and Gastric Surgery Unit,

CHUSJ - Oporto, Portugal

\section{ABSTRACT}

Gastrointestinal stromal tumors (GIST) are the most common mesenchymal tumors of the human gastrointestinal tract. They are derived from transformed neoplastic precursors of the interstitial cells of Cajal. They account for $0.1 \%$ to $3 \%$ of all gastrointestinal cancers. Up to $20 \%$ of cancers of the small bowel are GISTs. Less than $5 \%$ of cases are associated with hereditary predisposition, like Neurofibromatosis type I, Carney syndrome, and Familial GIST syndrome. The latter, is a rare autosomal dominant genetic disorder originated by germline gain-of-function mutations of KIT or PDGFRA. The study objectives were: to update the response to imatinib of family of our institution and review the families cases published in the literature with this syndrome. Review of the cases of Familial GIST syndrome published in literature and update of the only portuguese family be consultation of clinical processes. In the literature, we found 35 cases of unrelated families with this syndrome. This report is also an update on the only portuguese family with this syndrome and a good response to imatinib. The role of imatinib was not established in cases of familial GIST syndrome. In our opinion, it seems wise to use $400 \mathrm{mg} /$ day for an indefinite period. The objective is disease control and hindering the development of additional lesions.

Key words: germline GIST gene mutation, gastrointestinal cancer, surgery, imatinib, stroma tumours

\section{INTRODUCTION}

Gastrointestinal stromal tumors (GIST) were first recognized as a distinct Received: 08.04 .2019 Accepted: 15.06 .2019 morphologically as spindle cell, epithelioid, or occasionally pleomorphic mesenchymal tumors of the gastrointestinal tract that usually express the KIT protein (2). They are the most common mesenchymal tumors of the human clinicopathologic syndrome in 1983 by Mazur and Clark (1) and may be defined 
gastro-intestinal tract and are derived from transformed neoplastic precursors of the interstitial cells of Cajal (1). They develop mainly within gastric and small bowel muscular layers (3-4).

GISTs only account for $0.1 \%$ to $3 \%$ of all gastrointestinal cancers, but up they comprise $20 \%$ of cancers of the small bowel. They are found most frequently in the stomach $(60 \%)$, duodenum and small bowel (35\%), and less frequently in colon, rectum, esophagus, omentum and mesentery $(<5 \%)$ ). They occur mostly in the fifth to seventh decades of life and affect equally men and women (4).

This entity has a wide spectrum of clinical behaviors, spanning from indolent and curable disorders to highly malignant disease that metastasize and become lethal (1).

Annual incidence is between 10 to 20 cases per million $(2,4)$, and prevalence is 129 per million per year (4). No specific epidemiological risk factors for GIST have been described (5). More than $95 \%$ of GISTs are sporadic and less than $5 \%$ are associated with hereditary predisposition (3).

Approximately 95\% of sporadic GISTs have overexpression of the KIT protein (CD117), a transmembrane tyrosine kinase receptor. Activating somatic mutations of the proto-oncogenes KIT or plateletderived growth factor receptor alpha (PDGFRA) are mutually exclusive. These mutations occur in $85-90 \%$ of the cases, and are considered the primary genetic events in GIST pathogenesis. These genes code proteins with similar structure and function. KIT somatic mutations are present in $80-85 \%$ of the cases and occur predominantly in the juxtamembrane domain (exon 11; 60-70\%), followed by the extracellular domain (exon 9; $10 \%$ ), or, rarely, in the Kinase I and II domains (exons 13 and 17 , respectively; $2 \%$ ). Mutations in PDGFRA are detected in $5-10 \%$ of the sporadic cases and involve exon 12 (homologous to KIT exon 11; 1\%), exon 14 (homologous to KIT exon $13 ;<1 \%$ ), or exon 18 (homologous to KIT exon 17; 6\%) $(3,6)$. Both of genes (KIT and PDGFRA) are located within human chromosome 4q12 (4).

TNM classification has several limitations in GIST staging. Therefore its use is not recommended in this disease.

The standard approach to GIST tumors $\geq 2 \mathrm{~cm}$ in size is biopsy/excision, because they are associated with a higher risk of aggressive behavior. If there is an abdominal nodule not amenable to endoscopic assessment, laparoscopic/laparotomic excision is the standard approach (7).

Prognosis depends on mitotic rate, tumor size and location (gastric GISTs have a better prognosis than small bowel or rectal GISTs) (7).

\section{CASE REPORT}

Update of the only portuguese family with Familiar GIST syndrome, be consultation of clinical processes; and a comprehensive literature review was carried out, searching for of the cases of Familial GIST syndrome published in literature.

We present a case of a Caucasian 48 year-old woman, school worker, complaining of bloating, sporadic abdominal pain and heartburn for one year. She had a past medical history of depression and had suffered an unilateral oophorectomy years before (ovarian benign cyst).

There was a history of cancer in her family: Her mother had been operated 18 months before for metastatic GIST (segmental bowel resection and excisional biopsy of gastric exophytic tumor). The examination of the resected specimen revealed a mutation in 17 exon of c-kit gene [c.2458G > T (p.Asp820Tyr)], in more than $20 \%$ of tumor cells), and she had been started on Imatinib.

Due to the discovery of this mutation, our patient and some members of her family were submitted to genetic testing by another team, in another Hospital, and they published a paper about the mutation (3). However, the fraction of family we follow had not been included in this study (fig. 1). Our patient did carry this mutation.

We have found only 35 reports of unrelated families in world, with this syndrome (see table 1). In Portugal there is only one such family, living the Oporto area (3).

When we first saw our patient, she had already been submitted to upper GI endoscopy and computerized tomography (CT) scan of the abdomen.

Endoscopy revealed two polypoid tumors (of submucosa), in the gastric fundus, $10 \mathrm{~mm}$ each. The biopsy of those lesions did not reveal malignancy.

CT scan (fig. 2) revealed two polypoid tumors in the gastric fundus (about $14 \mathrm{~mm}$ ) and cyst inclusion on the site of a previous oophorectomy.

To complete the study, an endoscopic ultrasound was performed, which revealed two subepithelial lesions, both in the dependence of the muscularis mucosa, with 18 and $13 \mathrm{~mm}$ largest diameter, in the anterior wall of the body and proximal small curvature of the gastric cardia.

After discussing with the patient, an atypical gastrectomy was decided, to remove the lesions. During laparotomy, some millimetric lesions were 


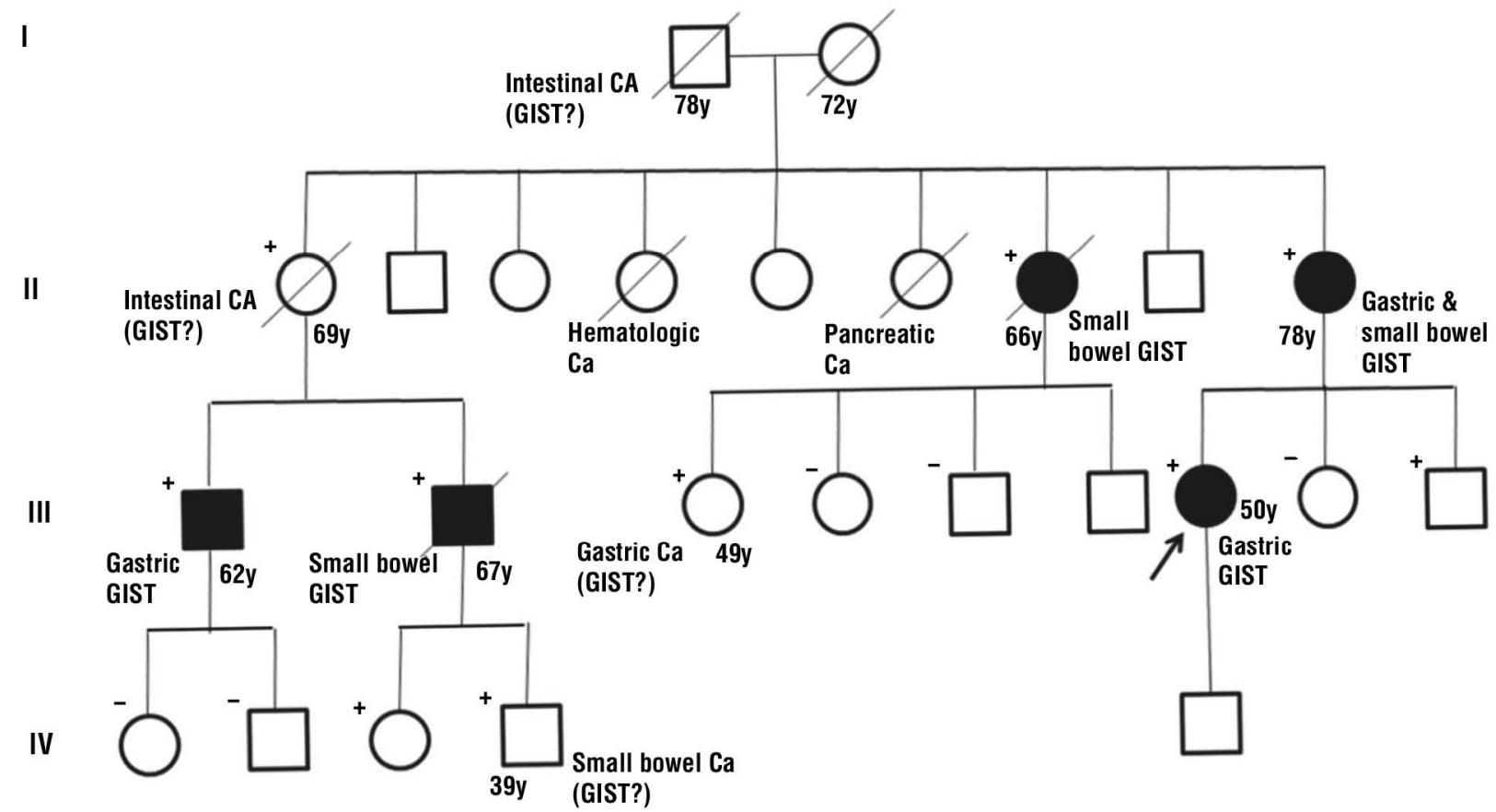

Figure 1 - Family tree. The arrow identifies our patient. The individuals fill the black indicate achievement by GIST disease. The individuals with a plus $(+)$ was submit to genetic study and was positive for mutation of c-kit (c.2458G $>T$ (p.Asp820Tyr)). Individuals with a minus (-) was negative in genetic study for mutation. The squares indicate the men and the circles the women.

found all over the gastric wall (fig. 3), and we decided to resect just the two major lesions.

After surgery, GIST was confirmed in the two lesions removed. After a consultation group with other specialties, we decided to proceed to imatinib treatment and imaging surveillance.

After 24 months with Imatinib and no evidence of disease progression, we performed a second-look surgery with total gastrectomy. Pathological examination of the stomach found no residual tumor, confirming the effectiveness of imatinib therapy. Since this was a case of familial GIST syndrome, our group decided to keep the treatment with Imatinib going.

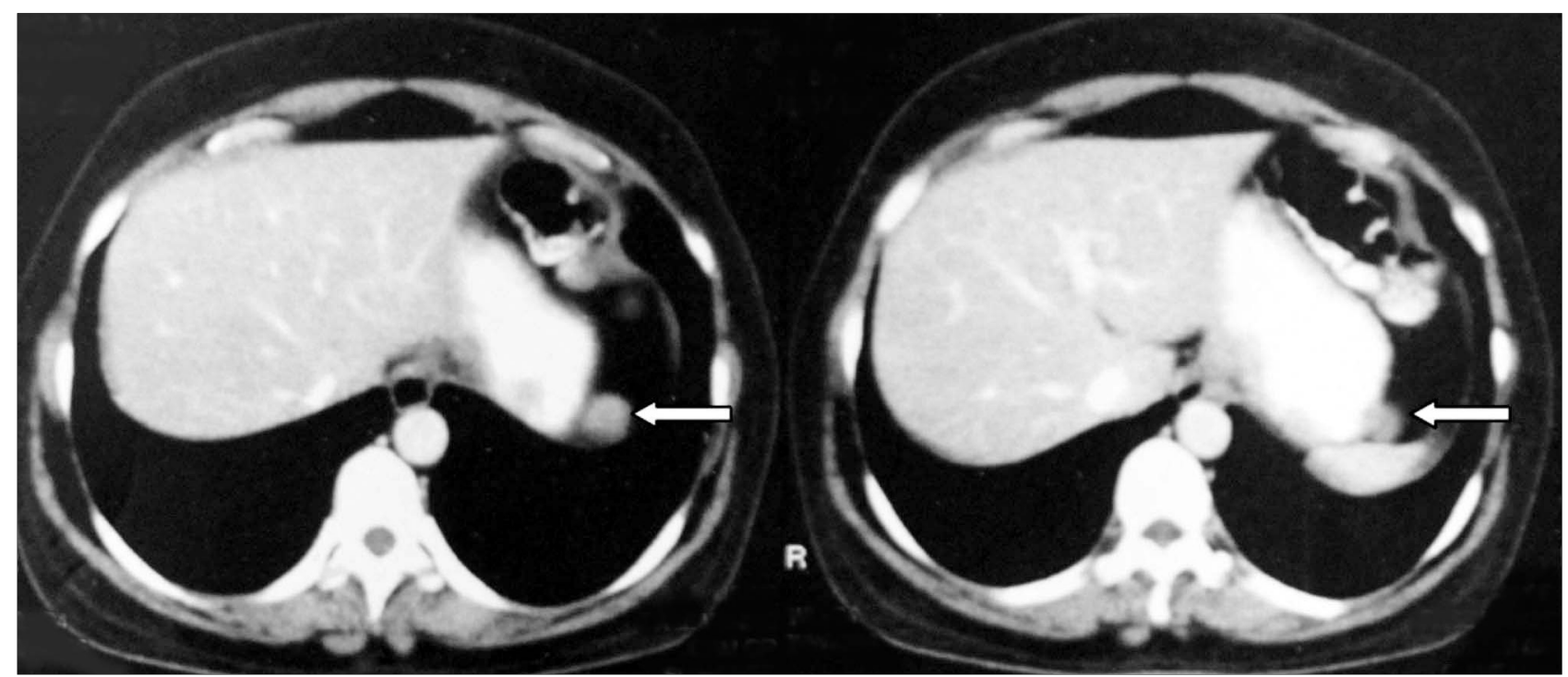

Figure 2 - Images of CT scan with pediculated tumor in gastric fundus (arrow) 
Table 1 - Families in world with Hereditary GIST syndrome with mutation, country, organs affected and accompanying signs and symptoms

\begin{tabular}{|c|c|c|c|c|c|c|c|c|c|}
\hline Gene & Exon & Mutation & Country & Organs affected & $\begin{array}{l}\text { Pigmentatio } \\
\mathrm{n} \text { anomalies }\end{array}$ & Dysphagia & $\begin{array}{l}\text { Urticaria } \\
\text { pigmentosa }\end{array}$ & Mastocytosis & Reference \\
\hline KIT & Exon 8 & p.Asp419del & German & Small intestine & No & Yes & No & Yes & [10] \\
\hline KIT & Exon 11 & p.Tyr553Cys & Japan & Small intestine/Stomach/Colon & No & No & No & No & [13] \\
\hline KIT & Exon 11 & p.W557R & Italy & Small intestine & Yes & Yes & No & No & [14] \\
\hline KIT & Exon 11 & p.W557R & Canada & Small intestine & Yes & No & No & No & [15] \\
\hline KIT & Exon 11 & p.V559A & Argentine & Small intestine/Stomach & Yes & Yes & No & No & [4] \\
\hline KIT & Exon 11 & p.V559A & USA & Small intestine & Yes & No & Yes & No & [1] \\
\hline KIT & Exon 11 & p.V559A & Korea & Small intestine & No & No & No & No & [17] \\
\hline KIT & Exon 11 & p.V559A & Italy & Small intestine/Stomach & Yes & No & Yes & Yes & [18] \\
\hline KIT & Exon 11 & p.V559A & Japan & Small intestine/Stomach & Yes & No & No & No & [19] \\
\hline KIT & Exon 11 & p.V559del & Japan & nd & Yes & No & No & No & [9] \\
\hline KIT & Exon 11 & p.V560G & Korea & Small intestine & Yes & No & No & No & [20] \\
\hline KIT & Exon 11 & p.V560del & Japan & Small intestine/Stomach & No & No & No & No & [8] \\
\hline KIT & Exon 11 & p.Q575_P577delinsH & Belgium & Rectum & No & No & No & No & [21] \\
\hline KIT & Exon 11 & p.L576_P577insQL & Spain & Small intestine/Stomach & Yes & No & No & No & [22] \\
\hline KIT & Exon 11 & p.L576P & Germany & Small intestine & Yes & Yes & No & No & [23] \\
\hline KIT & Exon 11 & p.d579del & USA & Small intestine & No & No & No & No & [24] \\
\hline KIT & Exon 11 & p.d579del & USA & Stomach & No & No & No & No & [25] \\
\hline KIT & Exon 11 & p.d579del & USA & Small intestine/Stomach & Yes & No & No & No & [26] \\
\hline KIT & Exon 11 & p.d579del & USA & Small intestine/Stomach & No & No & No & No & [27] \\
\hline KIT & Exon 11 & p.d579del & USA & Small intestine/Stomach & No & No & No & No & [27] \\
\hline KIT & Exon 13 & p.K642E & France & Small intestine & No & No & No & No & [28] \\
\hline KIT & Exon 13 & p.K642E & France & nd & Yes & Yes & No & No & [29] \\
\hline KIT & Exon 13 & p.K642E & France & nd & Yes & Yes & No & No & [29] \\
\hline KIT & Exon 13 & p.K642E & France & nd & Yes & Yes & No & No & [29] \\
\hline KIT & Exon 13 & p.K642E & UK & Esophagus/Stomach/Small intestine/Rectum & No & Yes & No & No & [30] \\
\hline KIT & Exon 13 & p.K642E & Spain & Stomach/Small intestine/Rectum & No & No & No & No & [31] \\
\hline KIT & Exon 13 & p.K642T & Japan & Small intestine/Stomach & No & Yes & No & No & [32] \\
\hline KIT & Exon 17 & p.D820Y & Japan & Small intestine/Stomach & No & Yes & No & No & {$[15-16]$} \\
\hline KIT & Exon 17 & p.D820Y & Irlanda & Small intestine/Stomach & No & Yes & No & No & [33] \\
\hline KIT & Exon 17 & p.D820Y & Portugal & Stomach/Small intestine/Rectum & No & No & No & No & [3] \\
\hline KIT & Exon 17 & p.D822Y & Germany & Small intestine/Stomach & nd & nd & nd & nd & [34] \\
\hline PDGFRA & Exon 12 & p.Y555C & Belgium & Small intestine & No & No & No & No & [35] \\
\hline PDGFRA & Exon 12 & p.V561D & USA & Small intestine/Stomach & No & No & No & No & [36] \\
\hline PDGFRA & Exon 14 & p.P653L & Italy & Stomach & No & No & No & No & {$[37]$} \\
\hline PDGFRA & Exon 18 & p.D846Y & France & Stomach & No & No & No & No & [38] \\
\hline
\end{tabular}




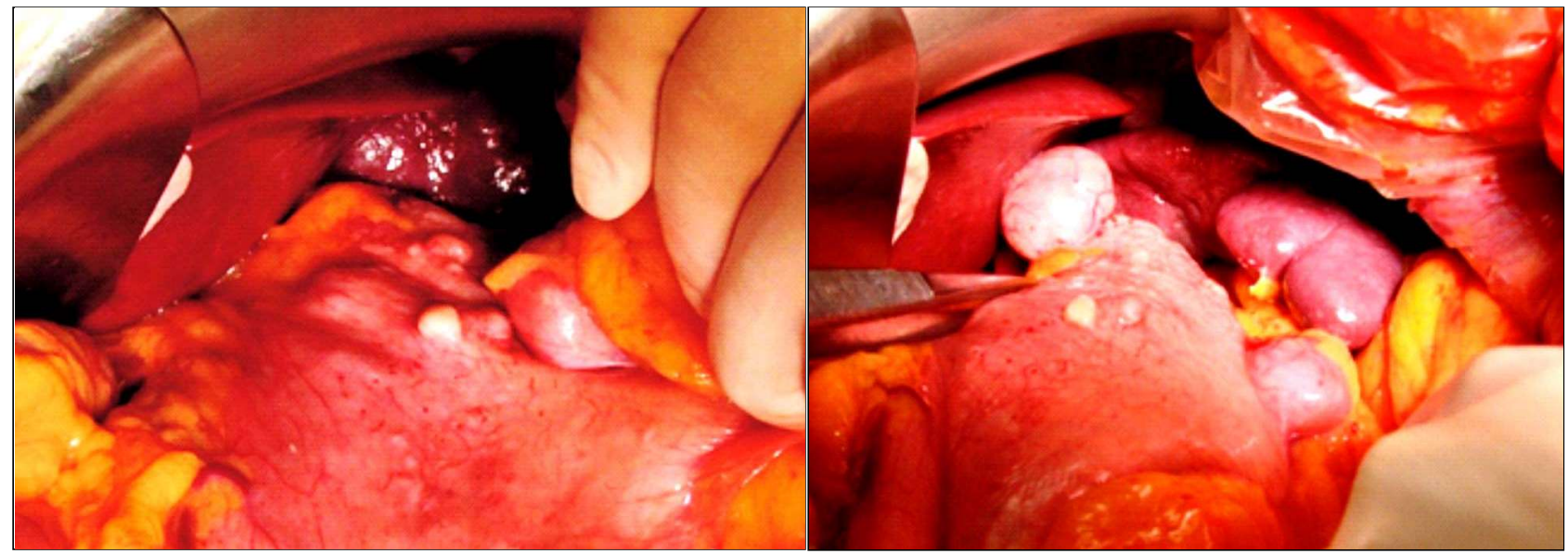

Figure 3 - Images of laparotomy with multiple gastric polypoid tumors

\section{DISCUSSION}

Hereditary predisposition to GIST is related with Neurofibromatosis Type I, Carney syndrome, and Familial GIST syndrome. The latter is a rare autosomal dominant genetic disorder originated by germline gain-of-function mutations of KIT or PDGFRA $(3,8)$. It was described for the first time in 1998 by Nishida and his group (5), with identification the mutation in exon 11 of KIT (9).

Most often, patients affected with Familial GIST develop multiple tumors at an early age, in contrast with sporadic cases that are characterized most often by solitary tumors that appear at a latter age. Other less common clinical features reported in patients with Familial GIST syndrome are skin hyperpigmentation, dysphagia, urticaria pigmentosa, and mastocytosis $(3,7,10-12)$. None of these were to be found in this family.

Among patients with familial GIST syndrome, the average age of index cases was 47 years (earlier than in sporadic cases). There is a documented case of a 15 year-old (11). There is no predominance of sex. Worldwide, there are four families with germline mutation on PDGFRA gene and the remaining 31 families with KIT gene mutations (one in exon 9, 19 in exon 13, seven in exon 13 and four in exon 17).

This Familial GIST syndrome had been studied and reported years before, but anyway this part of the family had not been submitted to genetic testing or put under surveillance. In fact, our patient and her mother had multiple lesions when they were submitted to surgery.

In our patient, although preoperative imaging suggested that the disease was locally contained, during laparotomy it was evident that there were multiple/metastatic GIST. Latter, imatinib treatment warranted a good response with complete remission in stomach.

In general, surgery is the standard in cases of non metastatic GISTs. The tumor must be removed en bloc with its pseudocapsule, to yield an adequate resection margin. Therefore, the goal of surgery is to accomplish an RO excision $(2,7)$. If RO surgery is not feasible, or if it only can be achieved at the expense of great mutilation or loss of function, pre-treatment with tyrosine kinase inhibitors (TKI), like imatinib followed by sparing surgery (cytoreduction), is standard. Optimal timing for surgery after maximal tumor response, is 6-12 months (7).

Adjuvant therapy with imatinib $400 \mathrm{mg} /$ day for three years, is the standard treatment for patients with a significant risk of relapse. Adjuvant therapy should not be considered when the risk is low (7).

In patients with metastatic disease, TKI are standard treatment (2). Imatinib has at least a 10fold more active favorable response than any other agent ever considered for treatment of GISTs (39). Treatment with TKI should be continued indefinitely, since treatment interruption is generally followed by relatively rapid tumor progression, even when lesions have been previously surgically excised (7).

In the case of confirmed progression, a dose escalation up to $800 \mathrm{mg} / \mathrm{day}$ and/or switch to a standard second-line treatment, another tyrosine kinase inhibitor - sunitinib - must be considered (7).

There is no data regarding the role of imatinib in preventing the development of GIST in Familial GIST. In some of these families, imatinib has an important role in maintaining the disease under control. We 
believe it can be used similar to nonhereditary GIST.

Typically, there are mutations which display an especially strong response to imatinib, like mutations of exon 11 of KIT as p.Asp579del mutation, compared to mutations of exon 9 of KIT.

Ávila et al. (2014) treated all gastrointestinal tumor-affected family members (p.V559A) with imatinib, which has caused a progressive reduction of the melanosis and of the tumor size (4). On the other hand, Bamba et al. (2015) (8) started imatinib if tumor progression is faster than expected, with half-dose of imatinib $(200 \mathrm{mg} /$ day $)$ and the size of all GISTs markedly was reduced and maintained stable for one year (p.V560del).

Graham and contributors (2007) maintained their patient (p.K642E) on imatinib treatment at $300 \mathrm{mg} /$ day (started at $400 \mathrm{mg} /$ day, but was reduced to $300 \mathrm{mg} /$ day because of intolerance) and disease remained stable after 19 months of treatment (until the publication of this article) (30).

Wozniak and contributors (2008), treated their patient (p.Q575 P577delinsH) with $400 \mathrm{mg} /$ day of imatinib and achieved either long-term partial response or stable disease after 58 months on treatment (21).

Regarding the family under study, Veiga et al. (2010) achieved partial response to imatinib and concluded that p.D820Y mutation was responsible for the weaker effect (3). We also achieved a good response in our patient (with complete remission of gastric lesions after 18 months of treatment and no relapse until now), with $400 \mathrm{mg} /$ day of Imatinib. This result might be explained by different cytogenetic progression pathways described in this family (3).

\section{CONCLUSION}

In conclusion, this case is about a rare condition in the world and the only affected family in Portugal. Furthermore this mutation is uncommon in Familial GIST syndrome (only one of the four documented cases of exon 17 mutation of KIT gene, in a total of 35 families).

All patients carrying a germline mutation of KIT or PDGFRA need to start endoscopic screening at a young age, since the condition may develop early in life (a case in a 15 year-old patient has been reported).

TKI, like imatinib, are an important therapeutic weapon in GIST cases. The role of this drug was not established in cases of familial GIST syndrome but, in our opinion, it seems wise to use it with a dosage of 400 $\mathrm{mg} /$ day continued indefinitely, since mutation was present in all of cells of patient. Imatinib may serve to control disease and may prevent the development of additional lesions.

\section{Ethical approval}

The terms of the Helsinki Agreement have been respected.

\section{Author contribution}

All of author had contributed to this article. All authors approved the final manuscript.

\section{Conflicts of interest and source of funding}

Authors have no conflict of interest to declare.

\section{REFERENCES}

1. Li FP, Fletcher JA, Heinrich MC, Garber JE, Sallan SE, CurielLewandrowski $\mathrm{C}$, et al. Familial gastrointestinal stromal tumor syndrome: phenotypic and molecular features in a Kindred. J Clin Oncol, 2005; 23:2735-43.

2. Joensuu H. Gastrointestinal stromal tumor (GIST). Annals of Oncology, 2006;17(10):280-6.

3. Veiga I, Silva M, Vieira J, Pinto C, Pinheiro M, Torres L, et al. Hereditary Gastrointestinal Stromal Tumors sharing the KIT Exon 17 germline mutation p.Asp820Tyr develop through different cytogenetic progression pathways. Genes, Chromosomes \& Cancer, 2010:49:91-8

4. Ávila SA, Peñaloza J, González F, Abdo I, Rainville I, Root E, et al. Dysphagia, melanosis, gastrointestinal stromal tumors and a germinal mutation of the KIT gene in an Argentine family. Acta Gastroenterol Latinoam, 2014:44:9-15.

5. Postow MA, Robson ME. Inherited gastrointestinal stromal tumor syndromes - mutations, clinical features, and therapeutic implications. Clinical Sarcoma Research, 2012;2:16

6. Rubin BP. Gastrointestinal stromal tumours: An update. Histopathology, 2006;48:83-96.

7. The ESMO/European Sarcoma Network Working. Gastrointestinal stromal tumours: ESMO Clinical Practice Guidelines for diagnosis, treatment and follow-up. Ann Oncol, 2014;25(3):iii21-6.

8. Bamba S, Hirota S, Inatomi O, Ban H, Nishimura T, Shioya M, et al. Familial and Multiple Gastrointestinal Stromal Tumors with Fair Response to a Half-dose of Imatinib. Intern Med,2015;54:759-64.

9. Nishida T, Hirota S, Taniguchi M, Hashimoto K, Isozaki K, Nakamura, $\mathrm{H}$, et al. Familial gastrointestinal stromal tumours with germline mutation of the KIT gene. Nat Genet, 1998;19(4):323-4.

10. Hartmann K, Wardelmann E, Ma Y, Merkelbach-Bruse S, Preussner LM, Woolwry C, et al. Novel Germline Mutation of KIT Associated With Familial Gastrointestinal Stromal Tumors and Mastocytosis. Gastroenterology, 2005;129:1042-6.

11. Demetri GD, Mehren Mv, Antonescu CR, DeMatteo, RP, Ganjoo KN, Maki RG, et al. NCCN Task Force Report: Update on the Management of Patients with Gastrointestinal Stromal Tumors. Journal of the National Comprehensive Cancer Network, 2010:8(S2):S1-S41

12. Isozaki K, Hirota S. Gain-of-Function Mutations of Receptor Tyrosine Kinases in Gastrointestinal Stromal Tumors. Current Genomics, 2006;7(8):469-75.

13. Nakai M, Hashikura Y, Ohkouchi M, Yamamura M, Akiyama T, Shiba $\mathrm{K}$, et al. Characterization of novel germline c-kit gene mutation, KIT-Tyr553Cys, observed in a family with multiple gastrointestinal stromal tumors. Laboratory Investigation, 2012;92:451-7. 
14. Robson ME, Glogowski E, Sommer G, Antonescu CR, Nafa K, Maki $\mathrm{RG}$, et al. Pleomorphic Characteristics of a Germ-Line KIT Mutation in a Large Kindred with Gastrointestinal Stromal Tumors, Hyperpigmentation, and Dysphagia. Clinical Cancer Research, 2004 10:1250-4.

15. Hirota S, Okazaki T, Kitamura Y, O'Brien P, Kapust, L, Dardick I. Cause of familial and multiple gastrointestinal autonomic nerve tumors with hyperplasia of interstitial cells of Cajal is germline mutation of the c-kit gene. Am J Surg Pathol, 2000;24(2):326-7.

16. Hirota S, Nishida T, Isozaki K, Taniguchi M, Nishikawa K, Ohashi A, et al. Familial Gastrointestinal Stromal Tumors Associated With Dysphagia and Novel Type Germline Mutation of KIT Gene. Gastroenterology, 2002;122(5):1493-9.

17. Kim H, SJ L, Park K, Yuh Y, Jang S, Choi J. Multiple gastrointestinal stromal tumors with a germline c-kit mutation. Pathol Int, 2005 55(10):655-9.

18. Beghini A, Tibiletti M, Roversi G, Chiaravalli A, Serio G, Capella C, et al. Germline Mutation in the Juxtamembrane Domain of the Kit Gene in a Family with Gastrointestinal Stromal Tumors and Urticaria Pigmentosa. Cancer, 2001;92(3):657-62.

19. Maeyama $H$, Hidaka E, Ota $H$, Minami S, Kajiyama M, Kuraishi A, et al. Familial gastrointestinal stromal tumor with hyperpigmentation association with a germline mutation of the c-kit gene. Gastroenterology, 2001;120:210-5.

20. Kang D, Park C, Choi J, Jin S, Kim H, Joo M, et al. Multiple gastrointestinal stromal tumors - Clinicopathologic and genetic analysis of 12 patients. Am J Surg Pathol, 2007;31(2):224-32.

21. Wozniak A, Rutkowski P, Sciot R, Ruka W, Michej W, DebiecRychter, M. Rectal gastrointestinal stromal tumors associated with a novel germline KIT mutation. Int. J. Cancer, 2008;122: $2160-4$.

22. Carballo M, Roig I, Aguilar F, Pol M, Gamundi M, Hernan I, et al. Novel C-KIT germline mutation in a family with gastrointestinal stromal tumors and cutaneous hyperpigmentation. Am J Med Genet A, 2005;132A(4):361-4.

23. Neuhann T, Mansmann V, Merkelbach-Bruse S, Klink B, Hellinger A, Höffkes $\mathrm{H}$, et al. A novel germline KIT mutation (p.L576P) in a family presenting with juvenile onset of multiple gastrointestinal stromal tumors, skin hyperpigmentations, and esophageal stenosis. Am J Surg Pathol, 2013;37:898-905.

24. Lasota J, Miettinen M. A new familial GIST identified. Am J Surg Pathol, 2007;31(5):816.

25. Tarn C, Merkel E, Canutescu AA, Shen W, Skorobogatko Y, Heslin M $\mathrm{J}$, et al. Analysis of KITMutations in Sporadic and Familial Gastrointestinal StromalTumors: Therapeutic Implications through Protein Modeling. Clin Cancer Res, 2005:11(10):3668-77.

26. Kleinbaum EP, Lazar AJ, Tamborini E, Mcauliffe JC, Sylvestre PB, Sunnenberg TD, et al. Clinical, histopathologic, molecular and therapeutic findings in a large kindred with gastrointestinal stromal tumor. Int J Cancer, 2008:122:711-8.

27. Jones DH, Caracciolo JT, Hodul PJ, Strosberg JR, Coppola D, Bui M M. Familial Gastrointestinal Stromal Tumor Syndrome: Report of 2 Cases With KIT Exon 11 Mutation. Cancer Control, 2015;22(1): 102-8.

28. Isozaki K, Terris B, Belghiti J, Schiffmann S, Hirota S, Vanderwinden JM. Germline-activating mutation in the kinase domain of KIT gene in familial gastrointestinal stromal tumors. American Journal of Pathology, 2000;157(5):1581-5.

29. Bachet J, Landi B, Laurent-Puig P, Italiano A, Le Cesne A, Lévy P, et al. Diagnosis, prognosis and treatment of patients with gastrointestinal stromal tumour (GIST) and germline mutation of KIT exon 13. Eur J Cancer, 2013:49(11):2531-41.

30. Graham J, Debiec-Rychter M, Corless CL, Reid R, Davidson R, White JD. Imatinib in the Management of Multiple Gastrointestinal Stromal Tumors Associated With a Germline KIT K642E Mutation. Arch Pathol Lab Med. 2007;131:1393-6.

31. Peña-Irun Á, Villa-Puente M, García-Espinosa R, Cavadas-López A. Familial gastrointestinal stroma tumor due to mutation in exon 13 (K642E) of the KIT gene. Med Clin (Barc), 2012;139(11):510-3.

32. Yamanoi K, Higuchi K, Kishimoto H, Nishida Y, Nakamura M, Sudoh $\mathrm{M}$, et al. Multiple gastrointestinal stromal tumors with novel germline c-kit gene mutation, K642T, at exon 13. Hum Pathol, 2014:45(4):884-8.

33. O'Riain C, Corless C, Heinrich M, Keegan D, Vioreanu M, Maguire D, et al. Gastrointestinal stromal tumors: insights from a new familial GIST kindred with unusual genetic and pathologic features. Am J Surg Pathol, 2005;29(12):1680-3.

34. Thalheimer A, Schlemmer M, Bueter M, Merkelbach-Bruse, S Schildhaus, H., Buettner, R., et al. Familial gastrointestinal stromal tumors caused by the novel KIT exon 17 germline mutation N822Y. Am J Surg Pathol, 2008;32(10):1560-5.

35. de Raedt T, Cools J, Debiec-Rychter M, Brems H, Mentens N, Sciot $\mathrm{R}$, et al. Intestinal Neurofibromatosis Is a Subtype of Familial GIST and Results From a Dominant Activating Mutation in PDGFRA. Gastroenterology, 2006;131(6):1907-12.

36. Pasini B, Matyakhina L, Bei T, Muchow M, Boikos S, Ferrando B, et al. Multiple gastrointestinal stromal and other tumors caused by platelet-derived growth factor receptor alpha gene mutations: A case associated with a germline V561D defect. The Journal of Clinical Endocrinology \& Metabolism, 2007;92(9):3728-32.

37. Ricci R, Martini M, Cenci T, Carbone A, Lanza P, Biondi A, et al. PDGFRA-mutant syndrome. Modern Pathology, 2015;28:954-64.

38. Chompret A, Kannengiesser C, Barrois M, Terrier P, Dahan P, Tursz $T$, et al. PDGFRA germline mutation in a family with multiple cases of gastrointestinal stromal tumor. Gastroenterology, 2004;126(1): $318-21$.

39. Lynch HT, Lynch JF, Shaw TG. Hereditary Gastrointestinal Cancer Syndromes. Gastrointest Cancer Res. 2011;4(S1):S9-S17. 